\title{
Frequency-Following Response (FFR) in Military Pilots
}

\author{
Graziela Maria Martins-Moreira ${ }^{1,2}$ Alessandra Spada Durante ${ }^{1(0)}$ \\ ${ }^{1}$ School of Medical Sciences, Santa Casa de Sao Paulo, São Paulo, SP, \\ Brazil \\ 2 Marinha do Brasil, Brazil \\ Address for correspondence Alessandra Spada Durante, SLP PhD, \\ Faculdade de Ciências Médicas da Santa Casa de São Paulo, Rua Dr. \\ Cesário Mota Junior, 61, 10 andar - São Paulo, SP, 01221-020, Brazil (e- \\ mail: alessandra.durante@fcmsantacasasp.edu.br).
}

Int Arch Otorhinolaryngol 2021;25(4):e517-e521.

\begin{abstract}
Keywords

- hearing

- electrophysiology

- cochlear nerve

- brainstem auditory evoked potentials

- speech perception

Introduction Good hearing in pilots, including central auditory skills, is critical for flight safety and the prevention of aircraft accidents. Pure tone audiometry alone may not be enough to assess hearing in the members of this population who, in addition to high noise levels, routinely face speech recognition tasks in non-ideal conditions.

Objective To characterize the frequency-following response (FFR) of a group of military pilots compared with a control group.

Methods Twenty military pilots in the Study Group and 20 non-pilot military personnel, not exposed to noise in their work, in the Control Group, all with normal hearing, aged between 30 and 40 years old, completed a questionnaire to assess their hearing habits, and their FFRs were measured with a /da/ syllable (duration 40 milliseconds, speed 10.9/s), at $80 \mathrm{~dB} N A$ in the right ear. All procedures were approved by the ethical committee of the institution. Statistical analysis was performed using the t-Student or Mann-Whitney tests for quantitative variables, and the Fisher or chisquared tests for qualitative variables, and a value of $p<0.05$ was considered to be statistically significant.

Results There was no significant difference between the groups regarding auditory habits. In the FFR, wave amplitudes $A(p=0.01)$ and $C(p=0.04)$ were significantly lower in the Study Group.

Conclusion Working as a military pilot can be a crucial factor in determining an individual's typical FFR pattern, demonstrated in the present study by statistically significant reductions in the amplitudes of the $A$ and $C$ waves.
\end{abstract}

\section{Introduction}

Brazilian military pilots hearing thresholds are tested every 6 months and must meet minimum criteria to ensure the ability to communicate with air traffic control (ATC). ${ }^{1-3}$ The noise of up to $110 \mathrm{~dB}$ SPL present at aerodromes and in-flight poses a risk to flight safety as it makes radio messaging difficult to understand. ${ }^{4-7}$ In addition, the working environment requires the airman to wear personal protective equip- ment (PPE) to prevent noise-induced hearing loss (NIHL), which, paradoxically, may compromise hearing acuity, reducing speech intelligibility and flight safety. ${ }^{8-10}$ Noiseinduced hearing loss receives more attention from researchers than central auditory functions, which are poorly studied in this population. ${ }^{11-16}$

Frequency-following response (FFR) is an electrophysiological response dominated by the rostral part of the brainstem and midbrain characterized by waves (A, C, D, E, F, and received

November 4, 2019

accepted

August 5, 2020

published online

December 8, 2020
DOI https://doi.org/ 10.1055/s-0040-1718525. ISSN 1809-9777.

\footnotetext{
(C) 2020. Fundação Otorrinolaringologia. All rights reserved.

This is an open access article published by Thieme under the terms of the Creative Commons Attribution-NonDerivative-NonCommercial-License, permitting copying and reproduction so long as the original work is given appropriate credit. Contents may not be used for commercial purposes, or adapted, remixed, transformed or built upon. (https://creativecommons.org/ licenses/by-nc-nd/4.0/) Thieme Revinter Publicações Ltda., Rua do Matoso 170, Rio de Janeiro, RJ, CEP 20270-135, Brazil
} 
O) that can be analyzed for their latencies, amplitudes and slope V/A, maturing at around eleven years old and gradually declining with age. ${ }^{17}$ This is a measure of evoked synchronous brain activity that reveals the integrity of complex sound processing in the brain and reflects auditory neurophysiological processes with a precision rarely offered by other tools in human neuroscience. Thus, FFR analysis provides a valuable measure of the clarity of the verbal auditory information processing of individuals and reflects the confluence of the cognitive, sensorimotor and auditory processing systems, reliably showing individual differences that reflect sensitivity to the sound environment and the way experiences shape hearing skills. ${ }^{18-26}$

The application of FFR in new and diverse areas holds a great deal of promise in relation to the study of communication. The potential for the systematic study of the effects of exposure to occupational noise using FFR is of particular interest and may contribute to a better understanding of how listening skills may be impaired by different noise environments. To enhance their clinical value, there is, therefore, a need for further research to assess whether the FFR traces of individuals exposed to noise have typical characteristics.

Thus, the aim of the present study was to characterize the components of FFR in military pilots.

\section{Method}

This is an observational, prospective, cross-sectional and analytical study, approved by the Research Ethics Committee of the Institution (CAEE 67606417.5.0000.5479). All participants signed an informed consent form. The required sample size was determined by the Statistics Service of the institution who calculated that a minimum size of 12 would provide a confidence interval (CI) of $95 \%$ and an error of $3 \%$. The study group (SG) comprised 20 military pilots and the control group (CG) 20 military personnel, all males with normal hearing, recruited in the air force hospital.

The following inclusion criteria were adopted for both groups: age between 30 and 40 years old; male; air conduction audiometric thresholds of $\leq 25 \mathrm{~dB} \mathrm{NA}^{27}$ with type $A$ tympanometry ${ }^{28}$ in both ears; transient otoacoustic emissions (TOAE) and distortion product otoacoustic emissions (DPOAE) with a signal to noise ratio (S/R) of $\geq 3 \mathrm{~dB} \mathrm{NPS}^{29}$ in at least 3 frequencies in both ears; and with no psychiatric, neurological, or syndromic changes identified by specialists in their annual clinical examinations.

The inclusion criteria specific for the SG was being an active Brazilian Air Force (FAB, in the Portuguese acronym) pilot with flight experience of at least 1,000 hours; and for the CG was being an active, non-pilot member of the military, without exposure to excessive noise in their work environments.

The exclusion criteria for both groups were: the presence of any conductive hearing losses and not completing the tests due to technical reasons or dropping out.

The participants completed a questionnaire, developed by the authors, regarding hearing habits. In the case of the SG, there were additional questions about the participant's career as a military airman. The subjects were then submit- ted to FFR using the protocol accessed in the SmartEP of the manufacturer IHS (Intellingent Hearing System, Miami, Florida, USA), comfortably seated in a reclining armchair in an acoustically treated, climate-controlled room. The skin was cleaned and the electrodes were then positioned at the vertex (active, positive electrode), forehead (earth) and right mastoid (reference, negative electrode). The absolute electrode impedances were $\leq 3 \mathrm{k} \Omega$. The participants were instructed to be calm and relaxed but without falling asleep. The protocol scan similar to the one used by Krizman et $\mathrm{al}^{23}$ in 2012 was presented: 3,000 syllable / da / sound stimuli lasting 40 milliseconds, velocity $10.9 / \mathrm{s}$, at $80 \mathrm{~dB} \mathrm{HL}$ with alternating phase in the right ear using an insertion earphone. The filters used were filter type 19 and bandpass $100-3,000 \mathrm{~Hz}$. The sum of the two responses, when present and replicable, was analyzed.

The analysis of the findings included the marking of seven waves ( $\mathrm{V}, \mathrm{A}, \mathrm{C}, \mathrm{D}, \mathrm{E}, \mathrm{F}$, and $\mathrm{O})$, generating latency and amplitude values for each wave. Two experts from different institutions with experience in FFR peak marking were invited to perform wave marking separately. The slope V/A value was calculated using the formula $=$ [VA Amplitude/VA Duration]. ${ }^{22}$ All data were tabulated in the Microsoft Office Excel (Microsoft Corporation, Redmond, WA, USA) program and descriptive analysis was performed using SPSS for Windows, Version 13, (SPSS Inc., Chicago, IL, USA).

Statistical analysis was performed for each quantitative variable using the t-Student (age, latency $C$, amplitudes $V, E$ and $F$, slope V/A) or the Mann-Whitney tests (latencies V, A, D, E, F and O; amplitudes A, C, D and O) for comparison of the two groups. For qualitative variables of the auditory habits questionnaire, the Fisher or chi-squared tests were used.

A $p$ value of $<0.05$ was considered to be statistically significant.

\section{Results}

\section{Auditory Profile of the Sample}

The mean age in the SG was $35( \pm 3.4)$ years old, ranging from 30 to 40.9 years old, and in the CG it was 35.1 ( \pm 2.7 ) years old, ranging from 30.7 to 39.5 years old, without any statistically significant differences.

There were also no significant differences in their responses to the hearing habits questionnaire (headphone use; non work-related noisy activity such as the use of firearms, motorboats, motorcycles or going to concerts or nightclubs; smoking; alcohol consumption and previous experience of playing a musical instrument). There was a low incidence of self-reported complaints of tinnitus and difficulty understanding speech in noise environments in both groups, without statistical differences.

The pilots in the SG had flown an average of 2,305 hours with $65 \%$ reporting that they currently used noise-canceling headsets; however, they stated that they had not always had this type of equipment, on average having only used them for a small part of their careers (280 hours or $12 \%$ ).

Most of the airmen studied (85\%) piloted fixed-wing aircraft and used PPE regularly when flying (95\%). A smaller 
Frequency-Following Response (FFR) in Military Pilots Martins-Moreira et al. 519

Table 1 Descriptive values of latency (ms) and slope (uV/ms) of frequency-following response components by group

\begin{tabular}{|c|c|c|c|c|c|c|c|}
\hline Wave & Group & Mean & Median & SD & Minimum & Maximum & p-value \\
\hline \multirow[t]{2}{*}{ V } & SG & 6.82 & 6.88 & 0.60 & 6.38 & 7.63 & \multirow[t]{2}{*}{0.67} \\
\hline & CG & 6.86 & 6.88 & 0.50 & 6.13 & 8.50 & \\
\hline \multirow[t]{2}{*}{ A } & SG & 8.62 & 8.57 & 0.67 & 7.88 & 9.88 & \multirow[t]{2}{*}{0.96} \\
\hline & CG & 8.77 & 8.50 & 0.89 & 7.75 & 11.25 & \\
\hline \multirow[t]{2}{*}{ C } & SG & 18.58 & 18.50 & 0.61 & 17.25 & 19.38 & \multirow[t]{2}{*}{0.12} \\
\hline & CG & 18.27 & 18.38 & 0.70 & 17.10 & 19.25 & \\
\hline \multirow[t]{2}{*}{$\mathrm{D}$} & SG & 23.68 & 23.50 & 0.72 & 22.88 & 25.88 & \multirow[t]{2}{*}{0.27} \\
\hline & CG & 23.29 & 23.50 & 0.82 & 20.50 & 24.63 & \\
\hline \multirow[t]{2}{*}{$E$} & SG & 32.42 & 32.25 & 0.70 & 31.50 & 34.25 & \multirow[t]{2}{*}{0.28} \\
\hline & CG & 32.71 & 32.75 & 0.81 & 31.25 & 34.75 & \\
\hline \multirow[t]{2}{*}{$\mathrm{F}$} & SG & 40.70 & 40.70 & 0.60 & 40.00 & 42.63 & \multirow[t]{2}{*}{0.09} \\
\hline & CG & 40.46 & 40.40 & 0.61 & 39.50 & 42.00 & \\
\hline \multirow[t]{2}{*}{$\mathrm{O}$} & SG & 48.79 & 48.88 & 1.01 & 45.25 & 50.38 & \multirow[t]{2}{*}{0.63} \\
\hline & CG & 48.89 & 48.88 & 0.51 & 47.75 & 50.25 & \\
\hline \multirow[t]{2}{*}{ Slope V/A } & SG & -0.12 & -0.12 & 0.04 & -0.21 & -0.04 & \multirow[t]{2}{*}{0.89} \\
\hline & CG & -0.12 & -0.12 & 0.09 & -0.22 & -0.04 & \\
\hline
\end{tabular}

Abbreviations:CG, control group; SD, standard deviation; SG, study group.

Table 2 Descriptive amplitude (uV) values of frequency-following response components by group

\begin{tabular}{|c|c|c|c|c|c|c|c|}
\hline Waves & Group & Mean & Median & SD & Minimum & Maximum & p-value \\
\hline \multirow[t]{2}{*}{ V } & SG & 0.13 & 0.13 & 0.03 & 0.06 & 0.18 & \multirow[t]{2}{*}{0.54} \\
\hline & CG & 0.12 & 0.10 & 0.05 & 0.06 & 0.25 & \\
\hline \multirow[t]{2}{*}{ A } & SG & -0.06 & -0.05 & 0.05 & -0.17 & 0.03 & \multirow[t]{2}{*}{0.01} \\
\hline & CG & -0.09 & -0.10 & 0.04 & -0.20 & -0.02 & \\
\hline \multirow[t]{2}{*}{ C } & SG & -0.09 & -0.08 & 0.08 & -0.35 & -0.02 & \multirow[t]{2}{*}{0.04} \\
\hline & CG & -0.11 & -0.11 & 0.04 & -0.19 & -0.04 & \\
\hline \multirow[t]{2}{*}{ D } & SG & -0.09 & -0.09 & 0.06 & -0.20 & 0.02 & \multirow[t]{2}{*}{0.46} \\
\hline & CG & -0.08 & -0.07 & 0.06 & -0.26 & -0.01 & \\
\hline \multirow[t]{2}{*}{ E } & SG & -0.11 & -0.10 & 0.05 & -0.22 & -0.03 & \multirow[t]{2}{*}{0.37} \\
\hline & CG & -0.12 & -0.12 & 0.05 & -0.19 & -0.05 & \\
\hline \multirow[t]{2}{*}{$\mathrm{F}$} & SG & -0.14 & -0.14 & 0.05 & -0.27 & -0.08 & \multirow[t]{2}{*}{0.61} \\
\hline & CG & -0.15 & -0.16 & 0.06 & -0.25 & -0.05 & \\
\hline \multirow[t]{2}{*}{$\mathrm{O}$} & SG & -0.11 & -0.12 & 0.06 & -0.24 & -0.01 & \multirow[t]{2}{*}{0.61} \\
\hline & CG & -0.12 & -0.11 & 0.06 & -0.27 & -0.02 & \\
\hline
\end{tabular}

Abbreviations:CG, control group; SD, standard deviation; SG, study group.

percentage (50\%) also wore PPE during external ground aircraft inspections.

\section{Frequency-Following Response}

- Tables 1 and $\mathbf{2}$ contain the descriptive statistics of FFR obtained by the agreement of two experts in $92.86 \%$ of the analyzed plots. In some cases (7.14\%), the two experts could not come to a consensus and a third expert made the final decision about these plots.
Comparisons of the latency of waves $\mathrm{C}$ and $\mathrm{E}$; the amplitude of waves V, E and F; and the slope V/A using the tStudent parametric test did not show any differences between the groups. For wave latencies V, A, D, F, and O; and for the amplitudes of waves $\mathrm{A}, \mathrm{C}, \mathrm{D}$, and $\mathrm{O}$, the nonparametric Mann-Whitney test was used, due to the possible influence of outliers and asymmetric distribution. There was a statistically significant difference in the amplitude of waves $A$ $(p=0.01)$ and $C(p=0.04)$ as shown in - Table 2 . 

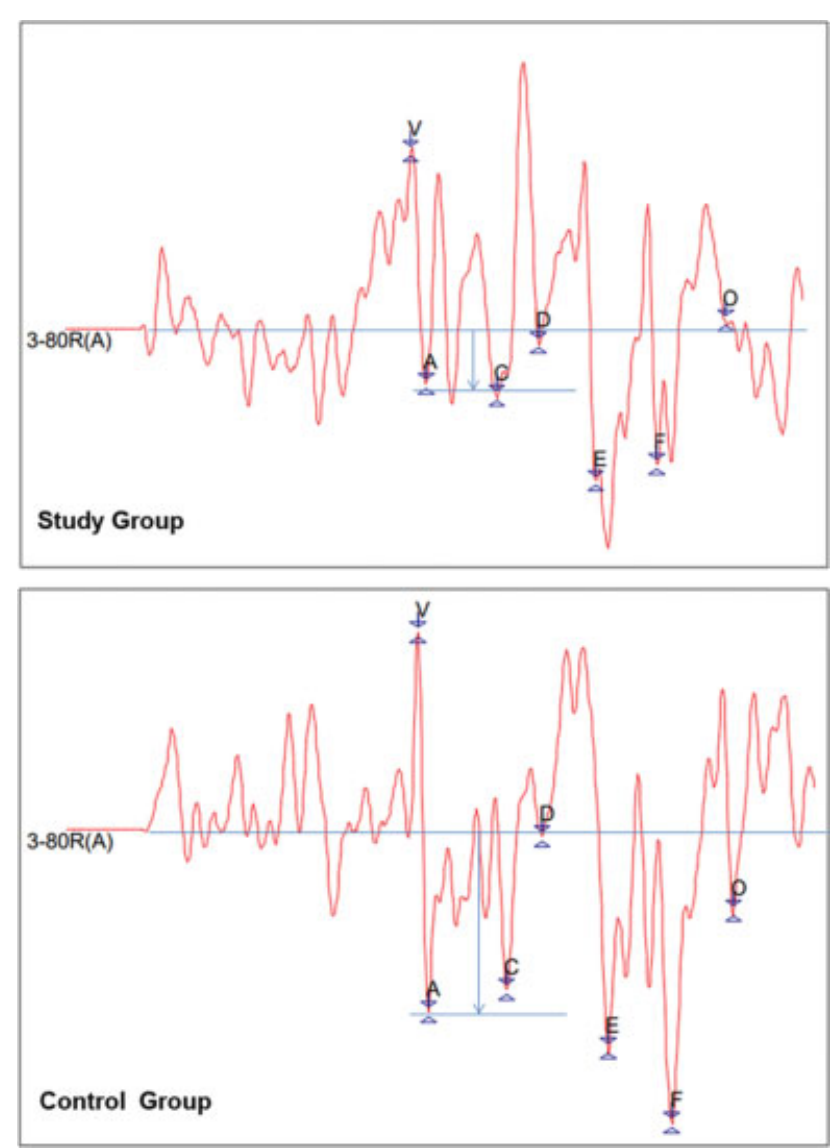

Fig. 1 Example of FFR tracing by group.

The amplitude differences between groups can be seen in -Fig. 1, which gives an example of the distinct wave morphology in one subject from each group, highlighting the amplitude difference of waves $\mathrm{A}$ and $\mathrm{C}$.

\section{Discussion}

The continuous routine exposure to speech in noise experienced by pilots generates a specific type of auditory task with as yet unknown consequences in relation to their auditory abilities; the present study aimed to map these through FFR performance analysis.

The hearing of military airmen is monitored by periodic assessments regulated by FAB health inspection stand$\operatorname{ards}^{1-3}$; however, these do not include a specific assessment of speech recognition in noise, a situation which is common as part of the operating routine of the pilots.

Military pilots between 30 and 40 years old, with an average of 2,305 flight hours and experience compatible with that of military personnel from other international air forces in the same age group were studied. ${ }^{30}$ The use of an upper age limit sought to prevent any interference from age-related hearing issues.

Among the subjects, $85 \%$ of pilots flew fixed-wing aircraft. Rotary-wing aircraft are noisier ${ }^{4}$ but less frequent in the population tested.
Although the use of PPE in flight may compromise the intelligibility of ATC messages, it is necessary and recommended. ${ }^{7-9}$ Ear plug PPE is still the most widespread and accessible form of hearing protection in the study population. Almost all the SG (95\%) reported using PPE when flying, which indicates that they are a population aware of the hearing risks involved in the profession. The use of noise-canceling headphones for high-performance hearing protection was used by $65 \%$ of the pilots surveyed. However, this technology was not available in the early years of their careers and was, therefore, used on average for only $12 \%$ of all flight hours.

The auditory habits questionnaire revealed that there were no differences between the two groups studied. Taking all the subjects $(n=40)$, it can be inferred that young Brazilian military adults have a high incidence of headphone use in leisure activities, and a low incidence of tinnitus and difficulty in speech perception in noise. These data are selfreported and are compatible with regular use of PPE and audiograms within normal limits. Experience with musical instruments, which could have a positive influence on auditory processing, ${ }^{20}$ was low in both groups, without statistically significant differences.

In the FFR analysis, although the $\mathrm{A}$ and $\mathrm{E}$ wave latencies of both groups are slightly delayed when compared with data in the literature, ${ }^{17,23}$ no differences in component latencies were found between the groups. The literature shows that the latency of FFR components is correlated with selfreported complaints of difficulty in understanding speech in noise. ${ }^{31}$ The positive and negative peaks of FFR are divided into those that are transient (waves V, A and C) and those that are sustained (waves D, E, F and O). Noise causes a disruption of speech perception, where the transient portion / d / is most affected while the sustained portion remains intact. Perception difficulties associated with the identification of consonants in noise can be attributed to decreased neural synchrony at the beginning of the stroke, while intact coding of the sustained portion allows for accurate perception of the vowel. ${ }^{32}$ In the present study sample, a low occurrence of self-reported complaints of being unable to understand speech in noise was observed. Further studies in the FFR field should consider the inclusion of speech perception tests and individuals with hearing complaints such as understanding speech-in-noise and tinnitus.

Statistical analysis of the data revealed a significant difference between the groups in the amplitude of the $A$ and $C$ waves. The $S G$ airmen presented a smaller $A$ amplitude than the CG. The presence of valley A together with peak $\mathrm{V}$ indicates the detection of the transient portion / d /, a decisive element for auditory discrimination and highly susceptible to noise. ${ }^{23,31}$ Its amplitude, greater or lesser, may be a result of sensory experiences, which are able to shape auditory abilities, such as listening to speech in noise. ${ }^{20}$ The SG also presented a significantly lower $\mathrm{C}$ amplitude than the CG, but both groups presented higher $C$ amplitudes than those reported in other studies with normal adults. ${ }^{23}$ Valley $\mathrm{C}$ represents the consonant-vowel transition, and in fact is not always considered in scientific research because it is inconsistent. ${ }^{17}$ Our results show a slight 
difference in the FFR of normal-hearing military airmen, demonstrated by the smaller amplitude of $A$ and $C$ waves.

Future research could include computational analysis and the correlation of FFR with speech recognition measures in different groups. This would help to develop FFR as a sensitive and specific biological marker for communication problems, with the potential to highlight differences between population samples. ${ }^{18}$

\section{Conclusion}

Working as a military pilot can be a crucial factor in determining the typical FFR pattern of an individual, demonstrated in the present study by statistically significant reductions in the amplitudes of the $\mathrm{A}$ and $\mathrm{C}$ waves.

\section{Funding}

This research did not receive any specific grant from funding agencies in the public, commercial, or not-forprofit sectors.

\section{Conflict of Interests}

The authors have no conflict of interests to declare.

\section{References}

1 Brasil. Agencia Nacional de Aviação Civil. Regulamento Brasileiro da Aviação Civil - RBAC n ${ }^{\circ}$ 67. Resolução ${ }^{\circ}{ }^{\circ} 211$, de 7 de dezembro de 2011 [Emenda 00], Resolução ${ }^{\circ}{ }^{420}$, de 21 de maio de 2017 [Emenda 01]. Disponível em: http://www.anac.gov.br/assuntos/legislacao/legislacao-1/boletim-de-pessoal/ 2017/17s1/anexo-ii-rbac-no-67-emenda-no-01/view. Acessed on $05 / 15 / 2019$

2 Brasil. Ministério da Defesa. Instrução do Comando da Aeronáutica - ICA 160-1, 2003

3 Brasil. Ministério da Defesa. Instrução do Comando da Aeronáutica - ICA 160-6, 2013

4 Kuronen P, Toppila E, Starck J, Pa A Kko Nen R, Sorri MJ. Modelling the risk of noise-induced hearing loss among military pilots. Int J Audiol 2004;43:79-84

5 Tobias JV. Binaural processing of speech in light aircraft. Technical Report $n^{\circ}$ FAA-AM-72-31 1972Washington, DC: Office of Aviation Medicine, Federal Aviation Administration; 1-6

6 Lahtinen TM, Huttunen KH, Kuronen PO, Sorri MJ, Leino TK. Radio speech communication problems reported in a survey of military pilots. Aviat Space Environ Med 2010;81(12):1123-1127

7 Matschke RG. [Communication and noise. Speech intelligibility of airplane pilots with and without active noise compensation]. HNO 1994;42(08):499-504

8 Yankaskas K. Prelude: noise-induced tinnitus and hearing loss in the military. Hear Res 2013;295:3-8

9 Wagstaff AS, Woxen OJ. Double hearing protection and Speech Intelligibility -Room for Improvement, RTO MP-19. In: Organização do Tratado do Atlântico Norte (RTO Meeting Proceedings 19): Current Aeromedical Issues in Rotary Wing Operation. 1998; MP-19, 33-31-33-35

10 Mozo BT, Gordon E, Murphy BA. An insert hearing protector with voice communications capability RTO. In: Organização doTratado do Atlântico Norte (RTO Meeting Proceedings 19): Current Aeromedical Issues in Rotary Wing Operation. 1998; MP-19, 34-31-34-34

11 Falcão TP, Luiz RR, Schütz GE, Mello MGS, Câmara VM. Perfil audiométrico segundo exposição de pilotos civis ao ruído. Rev Saude Publica 2014;48:790-796
12 Santos CCS, Juchem LS, Rossi AG. Processamento auditivo de militares expostos a ruído ocupacional. Rev CEFAC 2008; 10:92-103

13 Kujala T, Shtyrov Y, Winkler I, et al. Long-term exposure to noise impairs cortical sound processing and attention control. Psychophysiology 2004;41(06):875-881

14 Eggermont JJ. Effects of long-term non-traumatic noise exposure on the adult central auditory system. Hearing problems without hearing loss. Hear Res 2017;352:12-22

15 Le Prell CG, Brungart DS. Speech-in-Noise Tests and Suprathreshold Auditory Evoked Potentials as Metrics for Noise Damage and Clinical Trial Outcome Measures. Otol Neurotol 2016;37 (08):e295-e302

16 Hope AJ, Luxon LM, Bamiou DE. Effects of chronic noise exposure on speech-in-noise perception in the presence of normal audiometry. J Laryngol Otol 2013;127(03):233-238

17 Skoe E, Krizman J, Anderson S, Kraus N. Stability and plasticity of auditory brainstem function across the lifespan. Cereb Cortex 2015;25(06):1415-1426

18 Kraus N, Anderson S, White-Schwoch T. The Frequency-Following Response: a window into human communication. In: Kraus N, Anderson S, White-Schwoch T, Fay RR, Popper AN, eds. The Frequency-Following Response: A Window into Human Communication. Springer; 2017:1-15

19 Skoe E, Kraus N. Auditory brain stem response to complex sounds: a tutorial. Ear Hear 2010;31(03):302-324

20 White-Schwoch T, Kraus N. The Janus face of auditory learning. How life in sound shapes everyday communication. In: Kraus N, eds. The Frequency-Following Response: A Window into Human Communication. Springer; 2017:121-158

21 Chandrasekaran B, Kraus N. The scalp-recorded brainstem response to speech: neural origins and plasticity. Psychophysiology 2010;47(02):236-246

22 Wible B, Nicol T, Kraus N. Atypical brainstem representation of onset and formant structure of speech sounds in children with language-based learning problems. Biol Psychol 2004;67(03): 299-317

23 Krizman J, Skoe E, Kraus N. Sex differences in auditory subcortical function. Clin Neurophysiol 2012;123(03):590-597

24 Rocha-Muniz CN, Filippini R, Neves-Lobo IF, et al. O Potencial Evocado Auditivo com estímulo de fala pode ser uma ferramenta útil na prática clínica? CoDAS 2016;28:77-80

25 Fillipini R, Schochat E. Potenciais evocados auditivos de tronco encefálico com estímulo de fala no transtorno do processamento auditivo. Rev Bras Otorrinolaringol (Engl Ed) 2009;75:449-455

26 Smith SB, Krizman J, Liu C, White-Schwoch T, Nicol T, Kraus N. Investigating peripheral sources of speech-in-noise variability in listeners with normal audiograms. Hear Res 2019;371:66-74

27 Silman S, Silverman CA. Basic audiologic testing. In: Silman S, Silverman CA eds. Auditory diagnosis: principles and applications. San Diego: Singular Publishing Group; 1997:44-52

28 Paradise JL, Smith CG, Bluestone CD. Tympanometric detection of middle ear effusion in infants and young children. Pediatrics 1976;58(02):198-210

29 Gorga MP, Neely ST, Bergman BM, et al. A comparison of transientevoked and distortion product otoacoustic emissions in normalhearing and hearing-impaired subjects. J Acoust Soc Am 1993;94 (05):2639-2648

30 Kampel-Furman L, Joachims Z, Bar-Cohen H, et al. Hearing threshold shifts among military pilots of the Israeli Air Force. J R Army Med Corps 2018;164(01):46-51

31 Anderson S, Parbery-Clark A, White-Schwoch T, Kraus N. Auditory brainstem response to complex sounds predicts self-reported speech-in-noise performance. J Speech Lang Hear Res 2013;56 (01):31-43

32 Russo N, Nicol T, Musacchia G, Kraus N. Brainstem responses to speech syllables. Clin Neurophysiol 2004;115(09):2021-2030 